Luís Henrique da Costa Leão ${ }^{1}$ Luiz Carlos Fadel de Vasconcellos ${ }^{1}$

\section{Nas trilhas das cadeias produtivas: reflexões sobre uma política integradora de vigilância em saúde, trabalho e ambiente}

\author{
On the trails of commodity chains - reflections on a surveillance \\ policy integrating health, labor and environment
}

${ }^{1}$ Escola Nacional de Saúde Pública Sérgio Arouca, Fundação Oswaldo Cruz (Fiocruz), Rio de Janeiro, RJ, Brasil.

Contato:

Luís Henrique da Costa Leão.

Email:

luis_leao@hotmail.com

Financiamento: Programa de Excelência Acadêmica da Coordenação Nacional de Aperfeiçoamento de Pessoal de Nível Superior (Proex-Capes), conforme Edital de "Apoio Financeiro a Projetos de Discentes do Programa de Pós-Graduação Stricto Sensu em Saúde Pública da Escola Nacional de Saúde Pública”, 2010.

Ensaio baseado na dissertação de mestrado de Luís Henrique da Costa Leão intitulada "Nas trilhas das cadeias produtivas: subsídios para uma política integradora de vigilância em saúde", defendida em 2011 na Escola Nacional de Saúde Pública Sérgio Arouca.

Os autores declaram não haver conflitos de interesse.
Recebido: 02/03/2012

Revisado: 05/04/2013

Aprovado: 09/04/2013

\section{Resumo}

O objetivo deste ensaio é apresentar e discutir subsídios teóricos e práticos para uma política de vigilância em saúde, trabalho e ambiente sobre as cadeias produtivas. A partir das teorias ligadas à noção de complexidade e ao pensamento sistêmico em saúde coletiva, é discutida uma política integradora em alguns princípios: intrassetorialidade (integração das vigilâncias do SUS); intersetorialidade (articulação dos setores governamentais - previdência, meio ambiente, trabalho, agricultura, desenvolvimento, indústria e comércio exterior, entre outros - e setores não governamentais); controle social (incorporação dos saberes de atores e grupos da sociedade civil, comunidade local, trabalhadores, população e movimento social em geral); e transdisciplinaridade (diálogo de diversas disciplinas do campo científico e outros saberes). Estes princípios são potencialmente capazes de nortear uma vigilância integradora sobre os elos componentes de uma cadeia, principalmente considerando suas repercussões socioambientais nos elos de extração, transporte, produção, distribuição, consumo e descarte. Eleger as cadeias produtivas como meio de conexão de ações, serviços e estruturas do Estado com a sociedade é uma alternativa para possibilitar práticas de intervenção integradas sobre a complexa relação saúde, trabalho e ambiente, superando o modelo fragmentado e pontual.

Palavras-chave: produção de produtos; vigilância da população; vigilância sanitária de ambientes; vigilância em saúde do trabalhador.

\begin{abstract}
This essay purpose is to present and discuss theoretical and practical subsidies for a health, labor and environmental surveillance policy on commodity chains. Based on theories related to the notion of complexity and to the systemic thought in public health, it discusses an integrating policy based on the following principles: intra-sector (integration of Brazilian health system - SUS- surveillances); inter-sector (articulation of the governmental sectors - social security, environment, labor, agriculture, development, industry and foreign trade, among others, and non-governmental sectors); social control (incorporating the knowledge of actors and civil society groups, local community, workers, citizens and social movements in general); and trans-disciplinary (dialogue between various disciplines within science and other fields). These principles are capable to guide an integrating surveillance on the commodity chain links, mainly considering their social-environmental impacts on such links as: mining, transport, production, distribution, consumption and disposal. Choosing commodity chains as a strategy to connect governmental and society actions, services and structures is an alternative to enable integrated intervention practices on the complex health, labor and environment relations, overcoming the fragmentary and rigid model.
\end{abstract}

Keywords: production of products; population surveillance; environmental health surveillance; worker's health surveillance. 


\section{Introdução}

A vigilância em saúde é uma área de conhecimentos e intervenções do campo da saúde coletiva com vinculações institucionais com o Sistema Único de Saúde (SUS) cujo objetivo é atuar sobre os determinantes do processo saúde-doença nos grupos sociais.

Tem sido conceituada como análise permanente da situação da saúde, composta por um conjunto de ações que visam a controlar determinantes, riscos e danos à saúde das populações nos territórios, garantindo a integralidade da atenção (BRASIL, 2009).

Seu objeto não se restringe às doenças transmissíveis e aos fatores de risco, mas abrange os elementos sociais, econômicos e culturais que condicionam a saúde pública, sendo sua missão conhecer e intervir sobre esses determinantes.

Enquanto campo de práticas institucionais, a vigilância tem encontrado obstáculos em suas estruturas e dinâmicas de ação, tais como a ênfase na assistência à saúde ainda marcante no SUS, a falta de entrosamento entre as vigilâncias epidemiológica, sanitária e ambiental, a baixa articulação intersetorial e a pouca participação da população nos processos (LEÃO, 2011).

Além desses impasses, a vigilância tem o desafio de enfrentar uma série de questões sociais e sanitárias do atual momento histórico, marcado pela globalização da economia, pela degradação ambiental, pela exclusão social e pela precarização das condições de trabalho e vida.

Nas sociedades capitalistas globais, o Estado Democrático de Direito, junto com organizações da sociedade civil, necessita retomar a capacidade de intervir sobre os determinantes dos problemas de saúde e formular políticas de vigilância relacionadas à qualidade de vida, à solidariedade, à equidade, à democracia, ao desenvolvimento e à participação (FREITAS, 2003).

Uma das marcas da configuração econômica e social do século XXI é a formação de cadeias produtivas, que são processos de produção, comercialização e distribuição/exportação de bens e serviços organizados como um sistema. Esses processos são, por vezes, geograficamente dispersos nos territórios nacionais, ligados a demandas mundiais, que formam uma rede conectando os três setores da economia: a agricultura, a indústria e os serviços.

A engenharia de produção, a economia e a administração, entre outras áreas do conhecimento, utilizam a categoria "Cadeias Produtivas" e termos correlatos, como "Cadeia de Suprimento" e "Cadeia de Fornecimento" (PEROSA; VIEIRA; NITZSCHE,
2006; BIANCHINI; ASSUMPÇÃO, 2002), que em geral significam "um conjunto de etapas consecutivas pelas quais passam e vão sendo transformados e transferidos os diversos insumos" (PROCHNIK; HAGUENAUER, 2002, p. 144) e "uma rede de trabalho e processos de produção, cujo resultado final é um produto acabado" (HOPKINS; WALLERSTEIN, 1986, p. 159). Elas são compostas de diferentes processos de trabalho, fluxos de materiais e produtos, envolvendo diversas inserções de mão de obra formal, informal, entre outras.

Ao longo dos processos dessas cadeias, existe uma variedade de situações problemáticas do ponto de vista da saúde pública, pois, ao mesmo tempo em que geram riquezas, criam riscos e danos à saúde e ao ambiente em todo o ciclo produtivo.

Estudos acadêmicos e ações de movimentos sociais e organizações da sociedade civil têm demonstrado a necessidade de investigação de toda a cadeia produtiva, porque essa perspectiva de análise é um poderoso instrumento para o enfrentamento de situações de vulnerabilidades socioambientais.

No âmbito da sociologia do trabalho latino-americana, por exemplo, Abramo (2005) considera fundamental analisar a cadeia completa para a compreensão das novas modalidades de trabalho para além dos ambientes das fábricas e de situações de precariedade no trabalho na atualidade.

Relatórios, pesquisas e ações de movimentos sociais também tratam da questão. Em um relatório sobre os impactos da produção do etanol sobre a terra, o meio ambiente e a sociedade é enfatizado que:

[...] para além das normas legais, porém, outras bases que visem preservação ambiental e efetivação dos direitos fundamentais e do bem-estar social devem ser observadas ou estimuladas por atores presentes na cadeia produtiva de agroenergia. (CENTRO DE MONITORAMENTO DE AGROCOMBUSTÍVEIS, 2010, p. 62)

Veras e Cesara (2004) mostram que, na cadeia produtiva do aço brasileiro, pode-se verificar a existência de trabalho análogo à escravidão em carvoarias da selva amazônica, ligadas a grandes siderúrgicas nacionais que, contraditoriamente, possuem certificação de qualidade internacional.

Outra investigação que envolveu organizações não governamentais, a Comissão Nacional para a Erradicação do Trabalho Escravo (Conatrae) e a Organização Internacional do Trabalho (OIT) revelou cadeias produtivas de mercadorias brasileiras produzidas com esse mesmo tipo de trabalho. Foram identificados problemas em várias cadeias, como pecuária bovina, carvão vegetal, soja, algodão, ma- 
deira, milho, arroz, feijão, frutas, batata, cana-de-açúcar, entre outras (PACTO..., 2012).

Além de trazer à tona uma diversidade de problemas sociais, ambientais, trabalhistas, previdenciários e sanitários no âmbito das cadeias produtivas, essas pesquisas e relatórios têm contribuído para o desenvolvimento de mecanismos de regulação e controle que visam a enfrentar tais situações problemáticas.

A pesquisa acima relatada contribuiu para a criação do Pacto Nacional pela Erradicação do Trabalho Escravo no Brasil (2012), que recomenda intervenções sobre cadeias produtivas através da formalização das relações de trabalho entre produtores e fornecedores, cumprimentos das legislações trabalhistas, previdenciárias, de saúde e segurança, e prevê restrições comerciais a empresas ou pessoas identificadas nas cadeias que se utilizem de condições de trabalho degradantes.

A formulação de pactos neste molde, voluntários e dependentes da colaboração das empresas e dos atores institucionais, tem sido uma via de controle das cadeias produtivas.

Outras publicações divulgam problemas sociais e ambientais em cadeias de produção apostando na conscientização dos consumidores como forma de controle (ONG REPÓRTER BRASIL; PAPEL SOCIAL COMUNICAÇÃO, 2008). Esses estudos, marcados pelas lutas sociais de enfretamento da exploração humana e da degradação ambiental, objetivam informar aos consumidores a importância de rejeitarem os produtos disponíveis no mercado que tenham crimes ambientais e trabalhistas em suas cadeias produtivas. O relatório Conexões Sustentáveis São Paulo - Amazônia. Quem se beneficia com a destruição da Amazônia?, por exemplo, identificou várias empresas que mantiveram relações comerciais com proprietários e investidores rurais responsáveis por trabalho análogo à escravidão e a crimes ambientais na Amazônia (ONG REPÓRTER BRASIL; PAPEL SOCIAL COMUNICAÇÃO, 2008).

Nesta mesma direção, em 2011, foram apresentadas, em meios de comunicação de massa, irregularidades como o desmatamento ilegal e também o trabalho análogo à escravidão nas cadeias da carne, da soja e da madeira (MELO, 2011).

As complexidades das cadeias produtivas e suas repercussões na saúde dos trabalhadores e ambiental deflagram a necessidade de pesquisas e investigações sobre novos mecanismos de intervenção do Estado do ponto de vista da saúde pública, principalmente considerando a insuficiência do modelo de controle das cadeias produtivas via consumo/comércio e pactuações voluntaristas.
Existem poucos estudos que abordam essa temática sob a ótica da saúde coletiva na perspectiva da vigilância, ainda que as situações precárias no contexto das cadeias produtivas sejam marcantes no Brasil e demandem respostas na área da saúde, tanto no campo científico, quanto no institucional.

Leão (2011) verificou a escassez de pesquisas de vigilância em saúde sobre cadeias produtivas, indicando a necessidade de aprofundar as perspectivas teórico-metodológicas para suprir esta lacuna.

Daí a necessidade de subsidiar a vigilância com referenciais teóricos capazes de favorecer análises do tema no campo científico, bem como ações institucionais e propostas políticas.

O objetivo do presente ensaio é apresentar e discutir subsídios teóricos e práticos para uma política de vigilância em saúde, trabalho e ambiente sobre as cadeias produtivas. Apresenta referenciais teóricos para que ela integre a relação saúde, trabalho e ambiente tomando as cadeias produtivas como objeto central da ação. Acreditamos que a intervenção sobre as cadeias de produção possa consistir em uma perspectiva capaz de gerar novos processos de trabalho dos serviços de vigilância para enfrentar as problemáticas atuais do mundo do trabalho.

Esta discussão teórica e metodológica se baseia nos referenciais das abordagens sistêmicas e suas implicações para a vigilância em saúde no SUS (POSSAS, 2001; WALTNER-TOEWS, 2001; LEVINS; LOPEZ, 1999; MORIN, 1999; CAPRA, 1998; BERTALANFFY, 1986).

A partir das teorias ligadas à noção de complexidade e ao pensamento sistêmico (BERTALANFFY, 1986; MORIN, 1999), apresentamos uma revisão teórica da abordagem ecossistêmica e da ecossocial em saúde coletiva (MINAYO-GOMEZ; MINAYO, 2006; PORTO, 2005; KRIEGER, 2001; LEVINS; LOPEZ, 1999) para subsidiar as reflexões sobre uma proposta integradora para a vigilância.

Com base nesses referenciais, analisamos os princípios regentes da vigilância em saúde, suas principais normativas, bem como relatórios de fóruns e seminários organizados pelo Ministério da Saúde.

Também realizamos uma análise documental de documentos legais, pesquisas e relatórios produzidos por movimentos sociais e entidades da sociedade civil que têm como foco as cadeias produtivas.

A partir destes elementos, abordamos alguns princípios (intrassetorialidade, intersetorialidade, controle social e transdisciplinaridade) que contribuem para a estruturação de uma vigilância em saúde, trabalho e ambiente sobre as cadeias produtivas. 


\section{Perspectivas integradoras para a vigilân- cia em saúde}

No século XIX, a ciência moderna caracterizava-se pelo paradigma positivista, com ênfase na fragmentação de fenômenos como método para compreendê-los. Em sua trajetória, fez um movimento de "especialização", desenvolvendo disciplinas encapsuladas em seus universos particulares.

Tal ciência, segundo Edgar Morin, baseou-se em um pensamento que isola e separa: um pensamento "simplicador" e mutilador (MORIN, 1999).

No decorrer do século XX, diversas críticas surgiram sobre a fragmentação do campo científico e emergiram novas perspectivas de cunho holístico. A biologia, por exemplo, que por um momento analisou fenômenos vitais reduzindo-os a entidades atômicas e processos parciais, começou a investigar não somente partes e processos isolados, mas a organização, a ordem e as dinâmicas interações entre elas (BERTALANFFY, 1986).

Outras disciplinas caminharam nessa direção. Determinadas linhas da Psicologia, como a Gestalt, buscaram compreender os fenômenos mentais não como a soma das suas unidades elementares, mas como totalidades. Abordagens das Ciências Sociais, que concebiam a sociedade como a soma de indivíduos, também passaram a enfocar a sociedade, a economia e a nação como um todo superordenado às suas partes (BERTALANFFY, 1986). Essas formas mais holísticas de perceber e analisar os fenômenos influenciaram o surgimento da teoria sistêmica, na primeira metade do século XX. O biólogo alemão Ludwig von Bertalanffy contribuiu consideravelmente para o amadurecimento deste paradigma ao desenvolver a Teoria Geral dos Sistemas, sendo precedido pelas teorias da informação de Shanonn e Weaver e da Tectologia de Alexander Bogdanov, pesquisadores que também desenvolveram perspectivas sistêmicas (CAPRA, 1998).

As concepções de Bertalanffy estabeleceram o pensamento sistêmico como um movimento científico, pois ele acreditava que uma teoria geral dos sistemas ofereceria um arcabouço conceitual geral para unificar várias disciplinas científicas isoladas e fragmentadas (CAPRA, 1998).

Partindo da noção de que um sistema é um conjunto de elementos em interação, a Teoria Geral dos Sistemas busca oferecer princípios válidos para sistemas em geral, independente da natureza e da relação entre os elementos que os compõem (BERTALANFFY, 1986).
Essa teoria passou a ser aplicada às concepções de administração de organizações durante os anos 1960, havendo uma crescente difusão de estudos sobre formas, vantagens e configurações de rede intra e interorganizacionais (LEÃO; VASCONCELLOS, 2011).

O paradigma sistêmico focaliza a complexidade dos fenômenos e se baseia em dimensões que o diferem das teorias tradicionais. Ele sustenta a ideia de complexidade em substituição à de simplicidade dos fenômenos, contrapõe a noção de estabilidade e regularidade à perspectiva de instabilidade, e traz à tona a ideia de intersubjetividade na constituição da realidade, substituindo a crença em uma objetividade externa aos sujeitos (MINAYO-GOMEZ; MINAYO, 2006).

A partir da teoria sistêmica, o campo da saúde coletiva tem produzido novas abordagens teóricas, como a ecossistêmica e a ecossocial.

Diversos estudos nesse campo as identificam como importantes referenciais para compreender e intervir em fenômenos complexos, ligados a problemas ambientais, desenvolvimento sustentável, promoção da saúde, entre outros (BREILH, 2008; PORTO, 2007, 2001; POSSAS, 2001; WALTNER-TOEWS, 2001; LEVINS; LOPEZ, 1999).

A perspectiva ecossistêmica em saúde representa um referencial teórico relativamente novo no campo e surgiu como fruto de inquietações e preocupações que americanos e canadenses demonstravam em relação à área dos Grandes Lagos, que fora invadida por projetos agrícolas e industriais no processo de desenvolvimento econômico daquelas nações. Seu objetivo é desenvolver conhecimentos e estratégias de intervenção no que tange à relação saúde-ambiente a partir de realidades concretas, tendo como pilares centrais a transdisciplinaridade, a participação social e a equidade de gênero (MINAYO-GOMES; MINAYO, 2006).

Este enfoque é apropriado para a intervenção da saúde pública sobre os espaços de desenvolvimento humano, pois apresenta vantagens como: possibilidade de formação de redes, promoção de sociedades saudáveis em ecossistemas sustentáveis e atuação integrada em saúde (AUGUSTO, 2009).

De acordo com Minayo-Gomez e Minayo (2006), do ponto de vista metodológico, essa perspectiva traz desafios, dentre os quais: mudar o enfoque linear de diferentes disciplinas para um enfoque dinâmico de interação, exercitando a transdisciplinaridade; conseguir a participação dos agentes sociais envolvidos no problema em análise; e superar a acumulação de dados ou a descrição de problemas, identificando espaços de negociação intersetoriais e soluções práticas viáveis. 
A perspectiva ecossocial, por sua vez, foi proposta por Levins e Lopez (1999) e vem sendo defendida por alguns autores como Porto (2005) e Krieger (2001). Possui um enfoque abrangente que conecta aspectos sociais e ecológicos no entendimento de problemas de saúde das populações.

Tal perspectiva, longe de ser uma teoria totalizante, visa a produzir princípios integrais que orientem a investigação e as ações práticas (KRIEGER, 2001), facilitando a discussão integrada de questões de saúde, trabalho e ambiente.

Compreender problemas de saúde simultaneamente a partir de perspectivas ecológicas e sociais é fundamental para que propostas de desenvolvimento econômico e tecnológico possam resultar em balanços mais positivos entre os benefícios e os prejuízos dele decorrentes, seja para a saúde dos trabalhadores, da população em geral ou dos ecossistemas. (PORTO, 2005, p. 837)

Diante dos problemas socioambientais e das situações de vulnerabilidades nos territórios são necessárias reflexões e intervenções da saúde pública que considerem as diversas dimensões dos problemas, calcadas em referenciais mais amplos dos fenômenos (PORTO, 2007; AUGUSTO, 2003; BREILH, 2003; MINAYO; MIRANDA, 2002). A perspectiva holística poderia ser a chave para uma grande e necessária abordagem integral em saúde pública (LEVY, 1996).

Essas perspectivas sistêmicas no campo da saúde coletiva contribuem para a melhor compreensão dos fenômenos do mundo do trabalho e de suas inter-relações com a saúde da população e do meio ambiente.

No campo da vigilância em saúde, a lógica da teoria sistêmica, ao oferecer um enfoque holístico e contemplar a complexidade das relações entre as partes de qualquer sistema, pode subsidiar análises e intervenções integradoras, contribuindo para a superação da fragmentação do sistema de vigilância e das ações pontuais dos seus processos de trabalho. E, da mesma forma, pode proporcionar condições de abordar uma cadeia produtiva como um sistema de processos de produção, distribuição, comercialização e descarte de bens e serviços.

\section{Uma vigilância com referencial sistêmico}

A política de saúde do Estado brasileiro, inspirada nos ideais do Estado de Bem-Estar Social, fundamenta-se nos princípios e nas diretrizes de universalidade, integralidade, equidade, controle social, hierarquização e descentralização política e administrativa (RONCALLI, 2003).

Baseada nesses princípios, a vigilância em saúde tem o objetivo de gerar compreensão sobre os determi- nantes e condicionantes da saúde da população, bem como intervir neles, os quais são definidos pela legislação como alimentação, moradia, meio ambiente, trabalho, renda, educação, transporte, acesso aos bens e serviços essenciais, entre outros (BRASIL, 1990).

A forma como a sociedade se organiza, social e economicamente, determina as condições de vida da sua população, cabendo à vigilância conhecer-intervir nesses elementos, que ganham feições específicas em cada região e espaço geográfico, em contextos históricos, culturais e sociais específicos.

As cadeias produtivas movimentam a economia e seus processos de geração de bens e serviços interferem nesses elementos, repercutindo nas condições de habitação, transporte e trabalho das regiões e originando novos riscos à saúde e problemas socioambientais.

Essa realidade desafia as estruturas da vigilância pelas multiplicidades de fatores condicionantes, riscos e danos potenciais que as cadeias provocam: repercussões econômicas, sociais, ambientais, sanitárias e culturais; pela sua dimensão espacial, que extrapola limites jurisdicionais de atuação dos agentes de saúde; e pela complexidade de questões políticas e econômicas que envolvem: estruturas políticas e ações governamentais de incentivo às cadeias.

Isso demanda da vigilância em saúde pública estar referenciada em abordagens integradoras que contribuam para a ampliação das intervenções sobre os fatores condicionantes da saúde, indo além das doenças e dos fatores de risco, vinculando os processos saúde-doença aos processos de trabalho no escopo das cadeias produtivas.

Nesta direção, a articulação do setor saúde entre si e com outros setores governamentais e o controle social, por meio de uma abordagem transdisciplinar na produção de conhecimentos, é princípio de caráter holístico fundamental para a vigilância.

\section{Da fragmentação à articulação das vigilâncias (intras- setorialidade)}

Referenciais integradores podem subsidiar novos processos organizativos da vigilância em saúde no SUS, visando superar a segmentação das suas estruturas.

É possível afirmar que as práticas e as formas de organização da vigilância nos serviços de saúde pública não constituem um sistema integrado e articulado. Ao contrário, o paradigma da especialização entre as instâncias é dominante. O que se verifica é uma fragmentação das estruturas e das ações, separadas em compartimentos nomeados vigilância sanitária, epidemiológica, ambiental e de saúde do trabalhador, vigilância da violência, nutricional, entre outras. 
A vigilância epidemiológica em geral não se articula com as ações de fiscalização sanitária e não trabalha com informações geradas nos processos produtivos e indicadores de saúde do trabalhador, ambientais e sociais; a vigilância sanitária não incorpora a participação da sociedade em seus processos e focaliza produtos e serviços, abstraindo-se dos processos de produção, sem articulações intra e trans-setoriais, e com enfoque punitivo; a vigilância ambiental tende a examinar os processos produtivos "extramuros" das fábricas, desconsiderando a fonte primária intraprocessual de danos ambientais (VASCONCELLOS, 2007).

A divisão e a distinção entre os objetos de atuação e os objetivos institucionais específicos para cada ente da vigilância são necessárias para a organização do processo de trabalho, a definição de papéis e os recursos humanos e financeiros. O problema fundamental reside na falta de conexão entre as partes desse sistema, na fragilidade da cooperação para atuações conjuntas e nos obstáculos para o fluxo de informações.

Esforços para a implementação e a consolidação de mecanismos legais e técnicos de integração das vigilâncias podem ser percebidos nas Portarias do Ministério da Saúde no 3.252 de 2009 (BRASIL, 2009) e nํำ 104 de 2011 (BRASIL, 2011b), entre outras.

Essas legislações dispõem sobre as atividades da vigilância em saúde e as atribuições de cada ente do sistema, estabelecendo também diretrizes para as notificações compulsórias a fim de gerar informação epidemiológica. De certo modo, contribuem para superar esta problemática, pela ênfase na noção de "sistema de vigilância". No entanto, a fragmentação é flagrante em relação aos objetos de atuação, principalmente porque separa, de modo estanque, os campos saúde do trabalhador, saúde ambiental e saúde do consumidor. Assim, os fenômenos relativos a cada uma dessas áreas ficam sob a responsabilidade de entes e estruturas da vigilância desconexas entre si - vigilância em saúde do trabalhador, ambiental e sanitária, respectivamente.

Este olhar fragmentado das estruturas de vigilância deixa escapar o fato de que fenômenos de saúde-doença nos trabalhadores e na população em geral, bem como problemas ambientais, podem ser gerados simultaneamente e de modo sinérgico e ter vinculação direta com a existência de uma mesma cadeia produtiva no seu território de atuação. Ou seja, a vigilância fica fragmentada em torno de uma só fonte geradora dos problemas - a cadeia produtiva.

Conforme já asseverava Tambellini (1988), os três campos de preocupações e práticas, saúde do trabalhador, saúde ambiental e saúde do consumidor, são partes indissociáveis do processo produção-saúde. Nesse sentido, a intervenção da vigilância sobre toda a cadeia, de modo integrado, tem o potencial de agrupar esses três campos - saúde de quem consome os produtos finais, de quem trabalha nas etapas da cadeia e a saúde ambiental em todo o processo.

Uma vigilância integral que considere a saúde do trabalhador, a saúde ambiental e a saúde do consumidor, inclusive, é uma necessidade para o sistema de saúde a fim de ir além do atual modelo não sistêmico.

Nesta direção, a vigilância, em seus enfoques ambiental, epidemiológico, sanitário e de saúde do trabalhador, articular-se-ia em torno de uma cadeia, favorecendo a superação da fragmentação presente na atual configuração (Figura 1).

Uma questão importante a ser destacada também, no contexto das intervenções em saúde pública nas cadeias produtivas, é sua extensão territorial, porque demandam mais articulações nas estruturas da vigilância.

Figura 1 Integração da vigilância em saúde sobre cadeias produtivas

Vigilância da cadeia produtiva

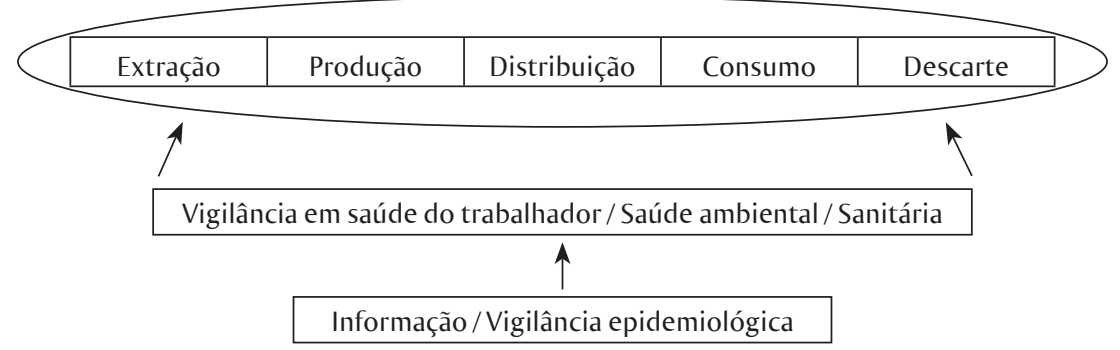

Fonte: Autores 
Uma cadeia produtiva não necessariamente se limita a um determinado município, estado ou até mesmo nação, podendo atravessar várias regiões gerando riscos, danos e agravos à saúde e ao meio ambiente em diversos espaços geográficos que extrapolam os limites de atuação territorial dos entes federativos do Estado.

A intervenção em toda a cadeia produtiva torna-se um elemento crucial para o enfrentamento de situações problemáticas em nível local que estejam conectadas a processos globais da economia capitalista contemporânea e submetidas a estruturas de poder político com práticas de inibição da atuação da vigilância. E, para isso, sólidas pactuações interfederativas são alternativas estratégicas, sendo necessário envolvimento de todos os âmbitos, como as Comissões Intergestores Bipartite (CIB) e Tripartite - CIT $^{2}$ (BRASIL, 1990) e outros espaços de pactuação. Isto também contribui para a sinergia dos entes da vigilância em saúde, remetendo às articulações não apenas intrassetoriais, mas também intersetoriais.

\section{Do isolamento à articulação intersetorial (interseto- rialidade)}

Sob o ponto de vista sistêmico, a complexidade, tanto da relação saúde, trabalho e ambiente, quanto dos fenômenos econômicos e sociais no âmbito das cadeias produtivas, não pode ser entendida como a soma de elementos isolados e analisada por setores governamentais separadamente.

São, assim, requeridas articulações intersetoriais capazes de subsidiar atuações sistêmicas sobre as cadeias de produção.

A intersetorialidade é considerada princípio fundamental para a construção de políticas públicas de saúde e se refere à articulação entre setores governamentais para ações de intervenção eficazes e resolutivas sobre objetos complexos:

\footnotetext{
Como prática de ação política e de gestão, a intersetorialidade parte da compreensão sistêmica dos problemas, com seus determinantes e condicionantes interligados e interdependentes. Na Saúde esse conceito é facilmente compreensível, pois a qualidade de vida é produto de um amplo conjunto de variáveis inter-relacionadas, associadas a diferentes setores da ação pública e social. (CONFERÊNCIA NACIONAL DE SAÚDE, 2004, p. 43)
}

Assim, uma política de vigilância integradora deve estabelecer mecanismos mais sólidos de intersetorialidade, buscando fortalecer as articulações entre setores do governo como o SUS, entre os ministérios da União e também nas instâncias estaduais e municipais.

No entanto, de que forma integrar? Como gerar as articulações entre estruturas distintas para que dialoguem e ajam em parcerias alcançando os resultados esperados?

Essas questões são cruciais porque a intersetorialidade é discurso corrente no campo da saúde pública, mas ainda carece de materialidade, pois são dominantes as práticas segmentadoras dos setores governamentais, frente às quais os agentes (ministérios e órgãos públicos) dificilmente conseguem gerar processos de atuação conjunta.

Consideramos que o foco nas cadeias produtivas pode conferir maior concretude à intersetorialidade na vigilância em saúde, trabalho e ambiente, sendo o eixo gerador da articulação dos setores governamentais.

A amplitude territorial da cadeia e suas dinâmicas de ação, bem como todos os seus processos perpassam os domínios dos diferentes órgãos reguladores dos setores do Estado, e este é um dos motivos capazes de gerar fios condutores de ações conjuntas e mecanismos de controle e intervenção intersetoriais.

Nesse sentido, as competências legais e técnicas de cada setor e seus órgãos específicos, em articulação protagonizada pelo setor saúde, seriam canalizadas para uma cadeia específica, gerando processos e ações em todos os seus elos nos estados e municípios que atravessa.

É preciso também considerar, que as ações setorializadas favorecem a perpetuação dos impactos ambientais, sociais e sanitários das cadeias produtivas, pois os recursos financeiros e humanos, as estruturas organizacionais e os processos de trabalho de cada setor isoladamente não são capazes de criar intervenções contínuas, sistemáticas e resolutivas.

Criar mecanismos mais sólidos de intersetorialidade sobre cadeias produtivas contribui para negar essa cultura de inspiração mecanicista e mutiladora que subsidia políticas e ações isoladas em processos organizacionais ensimesmados na máquina de governo.

Uma política de vigilância diante da complexa realidade a enfrentar - a relação saúde, trabalho e

\footnotetext{
${ }^{2} \mathrm{~A}$ CIB e a CIT são foros de negociação e pactuação entre gestores no que tange aos aspectos operacionais do SUS e tem como objetivos: decidir sobre os aspectos operacionais, financeiros e administrativos da gestão compartilhada do SUS, conforme os planos de saúde aprovados pelos conselhos; definir diretrizes de organização das redes de ações e serviços de saúde; e fixar diretrizes sobre as regiões de saúde, distrito sanitário, integração de territórios, referência e contrarreferência e demais aspectos vinculados à integração das ações e dos serviços de saúde entre os entes federados.
} 
ambiente nas cadeias produtivas - deve conferir materialidade às articulações entre os atores governamentais, incluindo também os sujeitos coletivos, as entidades da sociedade civil e os movimentos sociais em todos os processos.

\section{Do “participacionismo” à participação (controle social)}

O controle social foi estabelecido como um dos princípios fundamentais do SUS (BRASIL, 1990), institucionalizando a participação da população na formulação, implementação e avaliação das políticas de saúde. Esta participação abre espaços para a criação de políticas que sejam, de fato, públicas, como preconiza a saúde coletiva, e não apenas estatais:

\begin{abstract}
Esta, sem dúvida, foi a direção do movimento das políticas públicas de saúde que culminou no SUS. Com o conceito de saúde coletiva é a dimensão do público que é revigorada nas políticas de saúde. Não mais identificado a estatal, o público indica assim a dimensão do coletivo. Política pública, política dos coletivos. Saúde pública, saúde coletiva. Saúde de cada sujeito, saúde da população. (BENEVIDES; PASSOS, 2005, p. 566)
\end{abstract}

Os espaços de representação da sociedade nos processos de formulação, implementação e avaliação de políticas de saúde são os conselhos, as conferências e as comissões diversas. A questão problemática é que esses espaços correm o risco de se tornarem lócus de excessivo "participacionismo" e reduzida participação (MINAYO-GOMEZ, 2011), na medida em que os movimentos e as representações da sociedade assumam papéis meramente burocráticos.

A proposição de uma política integradora de vigilância em saúde, trabalho e ambiente implica na criação de formas de participação da sociedade para além de conselhos, conferências e comissões.

Um mecanismo importante para isso consiste no estabelecimento de fóruns permanentes e comissões nacionais e regionais articuladoras de movimentos sociais, representações de trabalhadores e conselhos de saúde, ambiente etc., acerca de cadeias produtivas.

Reunir movimentos e atores diversos em torno dos problemas de uma cadeia produtiva contribui para agrupar os movimentos sociais reivindicatórios e as lutas sindicais, contrariamente à setorialização e à dispersão de bandeiras de reivindicação.

Neste sentido, a atuação coletiva sobre uma cadeia produtiva gera possibilidades de investigações diversas em um processo contínuo de levantamento de situações relativas à saúde, trabalho, meio ambiente e às vulnerabilidades sociais, podendo levar à construção de ações de intervenção estratégicas.

A criação de espaços para a participação da sociedade na vigilância em saúde contribui, portanto, para uma política horizontal, conformando uma vigilância de caráter coletivo frente ao tecnicismo e ao corporativismo nas práticas de intervenção.

\section{Do tecnicismo disciplinar ao olhar complexo (trans- disciplinaridade).}

No campo da saúde pública, três modelos de construção do conhecimento se constituíram historicamente. O modelo multidisciplinar no século XIX, o interdisciplinar nas primeiras décadas do século XX e o transdisciplinar a partir da década de 1980 (LUZ, 2009). A transdisciplinaridade tende a ser o modelo dominante dada a complexidade do objeto da saúde pública - o processo de determinação de saúde/doença.

\begin{abstract}
A diferença interessante em relação a esse "modelo" de produção de conhecimento, ou paradigma científico, é que o conhecimento assim produzido pode integrar não apenas produção gerada a partir da pesquisa experimental, como da pesquisa quantitativa (epidemiológica, demográfica), qualitativa, e das pesquisas aplicadas, como no planejamento. Pode integrar também conhecimento gerado a partir da prática vivenciada pelas populações ou por usuários de serviços (ou pacientes), superando assim a clivagem senso comum $\times$ ciência, típica da modernidade. (LUZ, 2009, p. 309)
\end{abstract}

Como foi exposto, a perspectiva sistêmica emergiu como um paradigma contraposto ao modelo de produção de conhecimento baseado na especialidade, indo além da disciplinaridade vinculada ao "paradigma da simplificação" (MORIN, 1999).

A transdiciplinaridade, como importante aspecto da perceptiva sistêmica, contribui para a vigilância incorporar outros saberes nas ações de intervenção, invertendo a lógica operacional hegemônica baseada nas ações de técnicos especialistas e contribuindo também para a superação de paradigmas fragmentadores e disciplinares.

Uma política que promova intervenções integradas e alicerçadas em processos transdisciplinares articula conhecimentos técnicos, disciplinares e populares, produzindo saberes contextualizados capazes de subsidiar formas e alternativas de controle da cadeia produtiva.

Essa perspectiva rompe com o paradigma disciplinar de análise dos fenômenos e ressalta a viabilidade de construção de processos de vigilância de caráter complexo. Essa vigilância da complexidade, seguindo a compreensão de Edgar Morin (1999), busca criar meios e possibilidades de diálogo entre variados campos científicos e os saberes populares, os conhecimentos gerados por agentes de movimentos sociais, entre outros.

A vigilância somaria aos seus processos de geração de informação técnica, via notificações de agravos, doenças e demais ocorrências nas unidades de 
saúde, informações de cunho cultural que revelem vivências e expressões de vida e trabalho nos grupos humanos. Isso demanda a criação de novas modalidades de geração de informação de caráter transdisciplinar para a atuação da vigilância.

Em síntese, o referencial sistêmico subsidia reflexões sobre uma política de vigilância em saúde intrassetorial (integra as vigilâncias do SUS) e intersetorial (integra setores do governo), com fortalecimento do controle social (integra movimentos sociais e a população) e de caráter transdisciplinar (integra saberes).

\section{Uma vigilância integradora sobre cadeias produtivas}

A partir das abordagens sistêmicas que subsidiam uma vigilância holística, serão discutidas as possibilidades e as características de uma política de vigilância em saúde, trabalho e ambiente sobre as cadeias produtivas, considerando duas dimensões: a configuração de cada elo das cadeias e as situações de saúde, trabalho e ambiente, bem como as repercussões socioambientais de seu entorno.

\section{Da visão pontual ao olhar integral sobre a cadeia (cadeia em si)}

Uma política integradora de vigilância em saúde sobre as cadeias produtivas focaliza atuações constantes e sistemáticas sobre todos os seus elos, enfocando as especificidades de cada etapa e as possibilidades de controle e negociação em todas (Figura 2).

Essa política preconiza o conhecimento, a pesquisa, a intervenção, o acompanhamento contínuo, a criação de acordos, leis específicas e sanções comerciais sobre as cadeias de produção, engendrando processos deflagradores de riscos e danos à saúde pública e recomendando ações para sua erradicação e/ou controle.

No processo de vigilância, é primordial perceber os principais segmentos que compõem a cadeia para identificar as empresas e os setores envolvidos, os fluxos de atividades, operações e mão de obra, sem perder a dimensão do todo da cadeia. A visão integral sobre a cadeia facilita a articulação de mecanismos, agentes e meios de intervenção sobre ela.

As configurações das cadeias produtivas variam em função do tipo de bem produzido, das operações realizadas, da força de trabalho em atividade, das tecnologias empregadas, das políticas de incentivo e das características sócioculturais dos territórios que atravessam.

A cadeia produtiva do petróleo, por exemplo, é extremamente complexa do ponto de vista dos processos tecnológicos utilizados na extração, na produção e no refino. A extração ocorre geralmente em plataformas marítimas, sendo transportado para as refinarias, onde é processado e refinado, e em seguida distribuído para o mercado nacional e internacional, chegando ao consumidor. Já as cadeias de fruticultura são compostas por outras operações, emprega diferentes tecnologias, possui outro perfil de mão de obra, atravessa espaços territoriais diferenciados, bem como possui outras políticas de incentivo econômico. As ramificações de cada cadeia produtiva e a distribuição dos subprodutos envolvem fluxos de pessoas, processos e materiais distintos e, em geral, estão suscetíveis à precariedade do ponto de vista da saúde do trabalhador e ambiental.

Nesse contexto, a diversidade das cadeias produtivas precisa ser observada nos processos de intervenção por meio da análise e compreensão de suas especificidades e variáveis, como insumos utilizados, produto final, território usado, características da mão de obra, tecnologias empregadas, agentes envolvidos, instituições de apoio, entre outras coisas.

Figura 2 Etapas gerais de uma cadeia produtiva e processos de vigilância

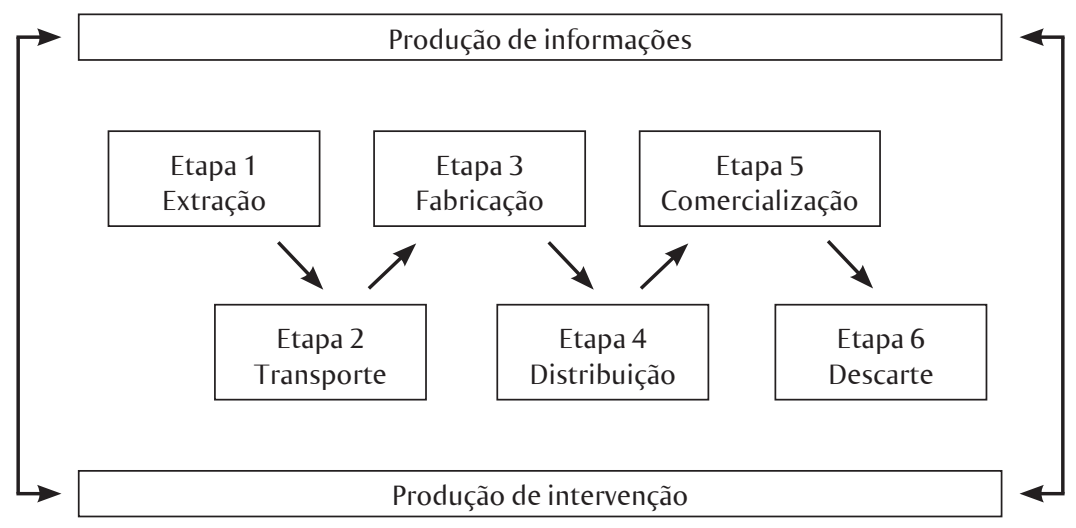

Fonte: Autores 
A identificação e a análise dos seus elos/etapas e de suas características podem revelar pontos-chaves para a criação de estratégias de controle com vistas a gerar processos de mudanças substanciais. Para isso, é necessário estruturar ações sobre todos os elos, produzindo informações através de diversos mapeamentos, caracterização dos processos, operações e tecnologias e identificando situações relativas à saúde, trabalho e ambiente. As informações geradas subsidiam a elaboração de ações interventivas de fiscalização sanitária, inspeção técnica, negociação coletiva, fóruns ampliados de debate, busca de soluções e demais ações necessárias para alcançar os objetivos desta modalidade de vigilância. Todo esse processo passa por apreender e determinar as configurações econômicas, espaciais/territoriais e políticas das cadeias produtivas.

As etapas e os elos que compõem as cadeias são formados por um conjunto de políticas de desenvolvimento, instituições e organizações governamentais e corporações, grupos de trabalhadores, insumos e materiais, equipamentos e maquinário, operações e atividades, que determinam os fluxos e movimentam a cadeia produtiva. Ao analisar uma cadeia de produção, é importante obter o conhecimento de todos esses arranjos técnicos, operacionais, políticos, financeiros e institucionais que estão envolvidos e a compõem.

Para obter um retrato histórico da sua configuração, esse processo de vigilância implica em determinar certas dimensões de seu funcionamento: a) Política e Econômica - detectar as políticas de incentivo e de desenvolvimento econômico da cadeia; b) Espacial e Territorial - dimensionar municípios, regiões, estados e, até mesmo, nações envolvidas nas etapas das cadeias de produção; c) Institucional - mapear quais organizações públicas e privadas estão envolvidas em cada elo, bem como as diversas empresas que fornecem serviços de apoio à cadeia; d) Tecnológica - identificar materiais, insumos, produtos, máquinas e equipamentos preponderantes na cadeia; e) Força de trabalho - verificar as diversas atividades presentes na cadeia e as características dos grupos de trabalhadores em cada uma delas.

Essas dimensões não esgotam a multiplicidade de fatores envolvidos, estando sujeitas a modificações e ampliações.

A partir dessas dimensões, essa vigilância em saúde, trabalho e ambiente se credencia para desenvolver um olhar integralizador, que abranja: a) o lócus de intervenção - todos os elos das cadeias produtivas, da extração ao descarte; b) os objetos alvos da ação - vulnerabilidades socioambientais, riscos, situações e eventos epidemiológicos, agravos, doenças, entre outros; c) as informações necessárias para a ação - geradas pelo setor governamental, pela sociedade civil, pelos saberes técnicos e populares etc.; d) os agentes da intervenção - vigilâncias articuladas, órgãos e "vigilâncias" que não pertencem à saúde pública, participação popular; e) os instrumentos de ação - mecanismos técnicos oriundos de diversas disciplinas do campo científico usados com o mesmo objetivo - contribuir para o mapeamento das cadeias produtivas e suas repercussões na saúde, no trabalho e no ambiente.

O setor saúde, neste contexto, assume o papel de principal impulsionador do conjunto de ações de vigilância, que envolve diversos níveis, como o nível legal (produção de legislações de controle das cadeias produtivas), o nível de acordos e negociações (processos de negociação coletiva, pactuações e compromissos éticos), o nível educacional (educação popular e saúde) e o nível fiscalizador e de inspeção (ações de intervenção em toda a cadeia).

Essa análise integral nos processos de intervenção implica em considerar também o ponto final das cadeias produtivas - o lixo. Processos de descarte de matéria prima, resíduos sólidos e rejeitos industriais ocorrem em diferentes etapas de uma mesma cadeia produtiva. $\mathrm{O}$ ponto aqui ressaltado se refere à necessidade de incorporação dos lixões e aterros sanitários como ponto final das cadeias produtivas e, portanto, alvos da ação da vigilância.

Além disso, os setores produtivos pertencentes a cada uma das cadeias possuem uma "capacidade econômica desproporcional à sua atuação na esfera da responsabilidade social" (VASCONCELLOS, 2007, p. 365), especialmente no caso do lixo. Desse modo, toda a cadeia produtiva deve ser responsabilizada pela destinação final de seus produtos.

\section{Dos fatores de risco às repercussões socioambientais (cadeia além de si)}

Além de considerar as configurações gerais da cadeia e as especificidades de cada elo que a compõe, a vigilância precisa atentar para as repercussões socioambientais no entorno das etapas produtivas, porque todo o processo de extração, produção, distribuição, comercialização e descarte têm repercussões sociais, ambientais e culturais nas comunidades. E esse fato não pode ser desprezado pela vigilância, considerando os referenciais ampliados da compreensão do processo saúde-doença no campo da saúde coletiva:

O velho modelo linear de compreensão do processo saúde doença orientador das práticas vigentes de saúde pública precisa ser substituído radicalmente por um modelo crítico que integra as dimensões sócio-culturais, ambientais e econômicas nos vários níveis hierárquicos da organização social, que vai da família à biosfera. (AUGUSTO, 2009, p. 56) 
Observar as situações de saúde, trabalho e ambiente nos processos das cadeias produtivas, sob o referencial integrador, requer a análise e a intervenção sobre a cadeia em si e além de si para integrar as externalidades dos processos produtivos nos territórios e nas dinâmicas de vida dos grupos sociais.

Neste sentido, é crucial dar atenção aos extremos das cadeias de produção, porque neles estão os pontos de maior vulnerabilidade social e ambiental configurando "territórios de exclusão" (PORTO, 2001, p. 245). As pontas das cadeias produtivas, em geral, formam espaços de vulnerabilidades onde se encontram formas de trabalho degradantes, envolvendo crianças, endividamento de trabalhadores e outros processos de exclusão social, fome, pobreza, migrações e prostituição. A precarização do trabalho sempre é maior nas etapas inicial e final e é onde o Estado está menos presente (LEÃO, 2011). Nos elos de industrialização e comercialização, existe maior cobertura de atores governamentais e ações institucionais, configurando setores econômicos-produtos mais "protegidos" pelo Estado.

Uma investigação, encomendada pela Secretaria Especial dos Direitos Humanos da Presidência da República (SEDH) a agências internacionais e entidades da sociedade civil, mapeou o relacionamento comercial de propriedades rurais e demonstrou a existência de trabalho análogo à escravidão na etapa inicial das cadeias produtivas estudadas (ORGANIZAÇÃO INTERNANCIONAL DO TRABALHO, 2010).

Outra pesquisa analisou o processo produtivo do café brasileiro e sua relação com a pobreza na região produtora, revelando que diversos problemas sociais, o descumprimento de legislação trabalhista, a ausência de controle e fiscalização sobre as condições de trabalho estão justamente na etapa inicial da cadeia de produção, pois "a responsabilidade social não chega à base da cadeia produtiva" (INSTITUTO OBSERVATÓRIO SOCIAL, 2003, p. 23).

Esta mesma cadeia de produção apresenta situações como transporte ilegal de trabalhadores, diversos acidentes de trabalho decorrentes das precárias condições laborais, desemprego e insegurança alimentar na entressafra. Os atores sociais envolvidos na ponta da cadeia, como agricultores e assalariados rurais, são os grupos mais vulneráveis (INSTITUTO OBSERVATÓRIO SOCIAL, 2003).
Situações extremas e condições degradantes atingindo comunidades e grupos de trabalhadores também são observadas na etapa final das cadeias produtivas, nas quais se encontram aterros sanitários e lixões.

Os problemas sociais e sanitários presentes nos extremos das cadeias produtivas dificilmente podem ser minimizados por ações isoladas, pontuais e fragmentadas dos atores governamentais e dos movimentos sociais. Neste sentido, a formulação de uma política de vigilância em saúde integradora seria uma alternativa estratégica. A integralidade da intervenção sobre as cadeias produtivas, articulando inclusive a atenção básica com a vigilância em saúde, trabalho e ambiente, representa um caminho, uma alternativa para responder de modo mais satisfatório às demandas sociais e sanitárias brasileiras.

Assim, um modelo integrador de vigilância em saúde focaliza não apenas os fenômenos intraprocessuais nas cadeias produtivas, mas inclui nas análises as repercussões sociais nas comunidades.

\section{Algumas experiências institucionais na direção da vigilância sobre cadeias produtivas}

Algumas experiências institucionais vêm sendo realizadas no Brasil, dirigidas pela Coordenação Geral de Saúde do Trabalhador da Secretaria de Vigilância em Saúde do Ministério da Saúde, baseadas nos pressupostos da intra e intersetorialidade, controle social e interdisciplinaridade.

No ano de 2010, entre os dias 16 e 18 de agosto, ocorreu, na cidade de Piracicaba, o seminário " $\mathrm{Da}$ saúde da cana à saúde do trabalhador: como melhorar as condições de vida e trabalho no setor canavieiro?”’3.

O evento foi promovido com o objetivo de (a) apresentar e discutir iniciativas de instâncias públicas, de setores da academia e de organizações sindicais e da sociedade civil na análise e prevenção dos agravos à saúde dos trabalhadores e ao ambiente nas atividades da cadeia produtiva sucroalcooleira e (b) proporcionar o intercâmbio de informações e experiências entre os diversos atores envolvidos, visando construir propostas intersetoriais de vigilância em saúde do trabalhador nessa cadeia produtiva.

Foram apresentados e debatidos relatos de pesquisa sobre a saúde do trabalhador e ambiental na cadeia

\footnotetext{
${ }^{3}$ Diversos representantes de órgãos governamentais e movimentos sociais participaram do encontro, como a Comissão Intersetorial de Saúde do Trabalhador Nacional (CIST), Conselho Nacional de Saúde, Secretaria de Vigilância em Saúde, Ministério Público do Trabalho, Fundação Oswaldo Cruz (Fiocruz), Fundação Jorge Duprat Figueiredo de Segurança e Medicina do Trabalho (Fundacentro), Confederação Nacional dos Trabalhadores na Agricultura (Contag), Universidade Federal do Rio de Janeiro (UFRJ), Universidade Estadual Paulista, Universidade Federal São Carlos, Fórum da Cidadania, Justiça e Cultura de Paz de Piracicaba, Federação dos Trabalhadores da Agricultura (Fetag), além de vários sindicatos. Disponível em: $<$ http:/189.28.128.179:8080/pisast/saude-do-trabalhador/eventos/oficina-da-201csaudeda-cana201d-a-saude-do-trabalhador-como-melhoraras-condicoes-de-vida-e-trabalho-no-setor-canavieiro/programa/programa-oficina-canavieira.pdf/view >. Acesso em: 15 ago. 2011.
} 
da cana-de-açúcar em várias regiões do Brasil - São Paulo, Mato Grosso, Paraíba, Paraná e Goiás -, fornecendo um panorama da produção de conhecimento sobre trabalho, ambiente e riscos neste setor.

Além das pesquisas, foram discutidas atuações de vigilância em saúde, ações de sindicatos, Ministério Público do Trabalho e de organizações da sociedade civil sobre aspectos diferentes da cadeia produtiva.

As discussões coletivas sobre as demandas e os riscos à saúde do trabalhador e ambiental presentes no setor sucroalcooleiro indicaram a necessidade de fortalecer as ações de intervenção em toda a cadeia produtiva, fato que pode contribuir para a formulação de políticas públicas de vigilância em saúde, trabalho e ambiente neste setor.

Meses depois foi realizada, nos dias 10, 11 e 12 de novembro na cidade de Cuiabá (MT), uma oficina nacional intitulada "Por uma melhoria das condições de vida e trabalho em setores do agronegócio”. Os objetivos foram apresentar e discutir as iniciativas em andamento de instâncias públicas, de setores da academia, de organizações sindicais e da sociedade civil na análise e prevenção dos agravos à saúde dos trabalhadores e ao ambiente decorrentes das atividades das cadeias produtivas da soja, milho, algodão e carne; propiciar o intercâmbio de informações e experiências entre os diversos atores envolvidos na construção de propostas intersetoriais de vigilância em saúde do trabalhador e ambiente; e fortalecer o controle social da vigilância em saúde dos trabalhadores do agronegócio (OFICINA..., 2010). A intenção foi reunir um conjunto de atores que pudessem contribuir para a formulação de estratégias de intervenção e construção de um esboço de protocolo que subsidiasse a atuação intersetorial dos vários segmentos envolvidos.

O encontro mostrou recentes atuações de instituições públicas e movimentos sociais sobre os temas trabalho, ambiente e riscos em setores do agronegócio com o foco em cadeias produtivas.

O documento final do encontro, inclusive, contém uma proposta com este objetivo: "Abordar a cadeia produtiva do agronegócio é necessário para fazer as vigilâncias atuarem de forma integrada. As vigilâncias se organizarão ao longo dos setores da cadeia” (BRASIL, 2010b, p. 2).

Duas outras propostas apontam nesta mesma direção: "Criar um plano nacional de vigilância de populações envolvidas na cadeia produtiva do agronegócio" e "realizar um seminário específico sobre a vigilância dos setores produtivos do agronegócio para a construção desse plano em níveis estaduais, culminando num encontro nacional” (BRASIL, 2010b, p. 2).
Essas duas experiências institucionais apontam para movimentos na direção da construção de políticas de vigilância sobre as cadeias produtivas.

Também já existem sinais, debates e normativas surgindo no campo político brasileiro na direção do estabelecimento de alianças entre governo e movimentos sociais para a construção de políticas públicas de saúde com este foco. A Lei no 12.305 de 2010 (BRASIL, 2010a), por exemplo, que institui a Política Nacional de Resíduos Sólidos, faz referência às cadeias produtivas, prevendo a responsabilidade compartilhada por todo o ciclo de vida do produto - o desenvolvimento do produto, a obtenção de matérias-primas e insumos, o processo produtivo, o consumo e a disposição final:

É instituída a responsabilidade compartilhada pelo
ciclo de vida dos produtos, a ser implementada de
forma individualizada e encadeada, abrangendo os
fabricantes, importadores, distribuidores e comer-
ciantes, os consumidores e os titulares dos serviços
públicos de limpeza urbana e de manejo de resíduos
sólidos. (BRASIL, 2010a, p. 12)

Por outro lado, algumas recentes conquistas legais do campo das relações saúde, trabalho e ambiente, ainda que tragam subsídios importantes, acabaram não avançando na direção de oferecer aportes para uma vigilância integral sobre as cadeias produtivas.

Em 2011, por exemplo, foi publicado o Decreto noㅡ 7.602, de 07 de novembro de 2011 (BRASIL, 2011a), dispondo sobre a Política Nacional de Segurança e Saúde no Trabalho (PNSST), e, em 2012, a Polícia Nacional de Saúde do Trabalhador e da Trabalhadora, com a Portaria do MS no 1.823, de 23 de agosto (BRASIL, 2012b).

Mesmo passando por diversas instâncias democráticas através de diálogos envolvendo o Estado e seus diferentes setores e a sociedade civil, o texto final dessas normativas deu pouca atenção à temática da vigilância em saúde, trabalho e ambiente.

Em detrimento deste fato, um exemplo específico sobre a vigilância das cadeias produtivas se encontra no documento institucional do Ministério da Saúde voltado para os serviços de saúde pública intitulado "Diretrizes para implementação da Vigilância em Saúde do Trabalhador no SUS”, que apresenta a abordagem da vigilância por cadeias produtivas:

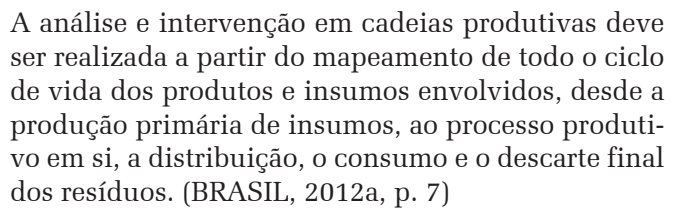

Segundo o documento, a abordagem contempla a avaliação das condições de trabalho, dos riscos, a identificação de medidas preventivas e a proposi- 
ção de alternativas aos modelos de desenvolvimento e produção.

Essas iniciativas são incipientes, porém têm potencial de desenvolvimento e merecem aprofundamento, no sentido de fortalecer proposições em torno de uma política de vigilância sobre cadeias produtivas.

\section{Conclusão}

Este ensaio buscou oferecer apontamentos para uma política de vigilância em saúde que tenha as cadeias produtivas como objeto central e ponto de articulação das instâncias da vigilância no SUS, dos setores governamentais e do controle social, considerando a relação saúde, trabalho e ambiente a partir das perspectivas teóricas sistêmicas.

O caráter integrador dessa política implica em preconizar o conhecimento, a análise e a intervenção em situações socioambientais e de saúde pública, e seus determinantes, no interior de cada elo das cadeias produtivas, bem como no seu exterior, considerando as repercussões em seu entorno.

As cadeias de produção são pontes estratégicas de ligação entre setores dispersos no aparelho de Es- tado, facilitando o fluxo, a troca, a integração e a articulação em favor das ações de vigilância em saúde, trabalho e ambiente.

Eleger as cadeias produtivas como meio de conexão de ações, serviços e estruturas é uma alternativa para possibilitar práticas de intervenção integradas sobre a complexa relação saúde, trabalho e ambiente, superando o modelo fragmentado e pontual.

A organização do sistema de vigilância em saúde, articulado e eficiente nas ações de intervenção, calcado em perspectivas integradoras, contribuiria para a superação das práticas fragmentadas do atual modelo. E como fator adicional também contribuiria para a integração dos entes federativos em um esforço comum na vigilância em saúde, coerente com a vocação doutrinária sistêmica do SUS.

Considerar a proposição de uma política integradora de vigilância em saúde voltada para a relação produção-distribuição-comercialização-descarte configura-se como uma proposta de vigilância holística sobre os elementos que constituem a própria organização da vida na sociedade contemporânea globalizada e pós-industrial. Acreditamos ser desafiadora, porém promissora, a possibilidade de seguir as trilhas das cadeias produtivas.

\section{Contribuições de autoria}

Leão, L. H. da C.: atuou na concepção inicial da pesquisa, na coleta e na análise de dados e na redação do artigo. Vasconcellos, L. C. F. de: concebeu a pesquisa e atuou na análise dos dados, na leitura crítica e na redação final do artigo.

\section{Referências}

ABRAMO, L. Cadeias produtivas, segmentação de gênero e novas formas de regulação: notas metodológicas a partir de uma experiência de pesquisa. In: GITAHY, L.; LEITE, M. P. (Org.). Novas tramas produtivas: uma discussão teórico-metodológica. São Paulo: Editora Senac São Paulo, 2005. p. 87-104.

AUGUSTO, L. G. S. (Org.). Saúde do trabalhador e sustentabilidade do desenvolvimento humano local: ensaios em Pernambuco. Recife: Editora Universitária UFPe, 2009.

AUGUSTO, L. G. S. Saúde e vigilância ambiental: um tema em construção. Epidemiologia e Serviços de Saúde, Brasília, v. 12, n. 4, p. 177-187, 2003.

BENEVIDES, R.; PASSOS, E. A humanização como dimensão pública das políticas de saúde. Ciência \& Saúde Coletiva, Rio de Janeiro, v. 10, n. 3, p. 561-571, 2005.

BERTALANFFY, L. V. Teoria general de los sistemas: fundamentos, desarrollo, aplicaciones. México: Fondo de Cultura Econômica, 1986.
BIANCHINI, V. K.; ASSUMPÇÃO, M. R. A diferenciação de produtos na cadeia produtiva do açúcar: o processo de produção de açúcares líquido e líquido invertido. In: ENCONTRO NACIONAL DE ENGENHARIA DE PRODUÇÃO, 22., 2002, Curitiba. Anais... Curitiba: Abepro, 2002. Disponível em: <http://www.agencia.cnptia.embrapa.br/Repositorio/ ENEGEP2002_TR11_0983_000fxg0zp8q02wyiv80soht 9hptpvrol.pdf $>$. Acesso em: 4 jun. 2013.

BRASIL. Decreto no 7.602 de 07 de novembro de 2011a. Dispõe sobre a Política Nacional de Segurança e Saúde no Trabalho - PNSST. Disponível em: <http://www.planalto.gov.br/ccivil_03/_ Ato2011-2014/2011/Decreto/D7602.htm>. Acesso em: 4 jun. 2013.

. Lei no 12.305 de 2 de agosto de 2010a. Institui a Política Nacional de Resíduos Sólidos; altera a Lei no 9.605, de 12 de fevereiro de 1998; e dá outras providências. Disponível em: < http://www.planalto. 
gov.br/ccivil_03/_ato2007-2010/2010/lei/112305.htm>. Acesso em: 4 jun. 2013.

. Ministério da Saúde. Diretrizes para implementação da Vigilância em Saúde do Trabalhador no SUS. Disponível em: $<$ http://189.28.128.179:8080/pisast/saude-dotrabalhador/desenvolvimento-de-acoes-de-saude-dotrabalhador-na-vigilancia-em-saude/diretrizes-visatfinal.pdf > . Acesso em: 10 jan. 2012a.

. Ministério da Saúde. Lei no 8.080 de 19 de setembro de 1990. Dispõe sobre as condições para a promoção, proteção e recuperação da saúde, a organização e o funcionamento dos serviços correspondentes e dá outras providências. Disponível em: <http://portal.saude.gov.br/portal/arquivos/pdf/ lei8080.pdf>. Acesso em: 4 jun. 2013.

. Ministério da Saúde. Oficina Nacional. Por uma melhoria das condições de vida, de trabalho e do ambiente em setores do agronegócio: encaminhamentos e propostas. Cuiabá, MT, 10 a 12 de novembro de 2010b. Mimeografado.

. Ministério da Saúde. Portaria no 104 de 25 de janeiro de 2011b. Define as terminologias adotadas em legislação nacional, conforme o disposto no Regulamento Sanitário Internacional 2005 (RSI 2005), a relação de doenças, agravos e eventos em saúde pública de notificação compulsória em todo o território nacional e estabelece fluxo, critérios, responsabilidades e atribuições aos profissionais e serviços de saúde. Diário Oficial [da] República Federativa do Brasil, Brasília, DF, 26 jan. 2011. Disponível em: <http://bvsms.saude.gov.br/bvs/ saudelegis/gm/2011/prt0104_25_01_2011.html>. Acesso em: 28 jun. 2013.

. Ministério da Saúde. Portaria no 1.823 de 23 de agosto de 2012b. Institui a política nacional de saúde do trabalhador e da trabalhadora. Diário Oficial [da] República Federativa do Brasil, Brasília, DF, 24 ago. 2012. Disponível em: <http://bvsms.saude.gov.br/ bvs/saudelegis/gm/2012/prt1823_23_08_2012.html>. Acesso em: 28 jun. 2013.

. Ministério da Saúde. Portaria no 3.252 de 22 de dezembro de 2009. Aprova as diretrizes para execução e financiamento das ações de Vigilância em Saúde pela União, Estados, Distrito Federal e Municípios e dá outras providências. Diário Oficial [da] República Federativa do Brasil, Brasília, DF, 23 dez. 2009. Disponível em: <http://portal.saude.gov.br/ portal/arquivos/pdf/portaria3252_da_vigilancia_em_ saude_0501_atual.pdf>. Acesso em: 28 jun. 2013.

BREILH, J. De la vigilancia convencional al monitoreo participativo. Ciência \& Saúde Coletiva, Rio de Janeiro, v. 8, n. 4, p. 937-951, 2003.

Pilhagens, ecossistemas e saúde. In:

BARCELLOS, C. (Org.). Território, ambiente e saúde. Rio de Janeiro: Fiocruz, 2008. p. 159-180.
CAPRA, F. A teia da vida: uma nova compreensão científica dos sistemas vivos. São Paulo: Cultrix, 1998.

CENTRO DE MONITORAMENTO DE

AGROCOMBUSTÍVEIS. ONG Repórter Brasil. O Brasil dos agrocombustíveis: impactos das lavouras sobre a terra, o meio e a sociedade - Cana 2009. [São Paulo]: ONG Repórter Brasil, 2010. Disponível em: <http:// reporterbrasil.org.br/documentos/o_brasil_dos_ agrocombustiveis_v6.pdf $>$. Acesso em: 4 jun. 2013

CONFERÊNCIA NACIONAL DE SAÚDE, 12., 2003. Conferência Sérgio Arouca. Relatório Final. Brasília, DF: Ministério da Saúde, 2004. (Série D. Reuniões e Conferências). Disponível em: <http://sna.saude. gov.br/download/rel\%20final\%2012a\%20CNS.pdf>. Acesso em: 28 jun. 2013.

FREITAS, C. M. Da vigilância da saúde para a promoção da saúde. In: CZERESNIA, D.; FREITAS, C. M. (Org.). Promoção da saúde: conceitos, reflexões, tendências. Rio de Janeiro: Fiocruz, 2003. p. 141-159.

HOPKINS, T. K.; WALLERSTEIN, I. Commodity chains in the world economy prior to 1800. Review (Fernand Braudel Center), v. 10, n. 1, p. 157-170, 1986.

INSTITUTO OBSERVATÓRIO SOCIAL. Café e pobreza - Sara Lee: teoria e prática na responsabilidade social. São Paulo: IOS, 2003.

KRIEGER, N. Theories for social epidemiology in the 21st century: an ecosocial perspective. International Journal of Epidemiology, v. 30, n. 4, p. 668-677, 2001.

LEÃO, L. H. C. Nas trilhas das cadeias produtivas: subsídios para uma política integradora de vigilância em saúde. 2011. 192 f. Dissertação (Mestrado em Saúde Pública)-Escola Nacional de Saúde Pública Sérgio Arouca, Fundação Oswaldo Cruz, Rio de Janeiro, 2011.

LEÃO, L. H. C.; VASCONCELLOS, L. C. F. Rede Nacional de Atenção Integral à Saúde do Trabalhador (Renast): reflexões sobre a estrutura de rede.

Epidemiologia e Serviços de Saúde, Brasília, v. 20, n. 1, p. 85-100, 2011.

LEVINS, R.; LOPEZ, C. Toward an ecosocial view of heath. International Journal of Health Services, v. 29, n. 2, p. 261-293, 1999.

LEVY, B. S. Toward a holistic approach to public health surveillance. American Joumal of Public Health, v. 86, n. 5, p. 624-625, 1996.

LUZ, M. T. Complexidade do Campo da Saúde Coletiva: multidisciplinaridade, interdisciplinaridade, e transdisciplinaridade de saberes e práticas - análise sócio-histórica de uma trajetória paradigmática. Saúde \& Sociedade, São Paulo, v. 18, n. 2, p. 304-311, 2009.

MELO, L. Desmatamento e escravidão no rastro de carne, soja e madeira. O Globo, Rio de Janeiro, 23 fev. 2011, Seção Economia, 2. ed., p. 25. 
MINAYO, M. C. S.; MIRANDA, A. C. (Org.). Saúde e ambiente sustentável: estreitando nós. Rio de Janeiro: Fiocruz, 2002.

MINAYO-GOMEZ, C. Campo da saúde do trabalhador: trajetória, configuração e transformações. In: GOMEZ, C. M.; MACHADO, J. H. M.; PENA, P. G. L. (Org.). Saúde do trabalhador na sociedade brasileira contemporânea. Rio de Janeiro: Editora Fiocruz, 2011. p. 23-34.

MINAYO-GOMES, C.; MINAYO, M. C. S.

Enfoque ecossistêmico de saúde: uma estratégia transdisciplinar. Interfaces, Revista de Saúde, Meio Ambiente e Sustentabilidade, São Paulo, v. 1, n. 1, p. 1-19, ago. 2006.

MORIN, E. Introdução ao pensamento complexo. Lisboa: Instituto Piaget, 1999.

OFICINA Agronegócio. Cuiabá, MT, 2010. Disponível em: <http://pisast.saude.gov.br:8080/pisast/saudedo-trabalhador/eventos/oficina-por-uma-melhoriadas-condicoes-de-vida-e-trabalho-em-setores-doagronegocio-cuiaba-mt.> Acesso em: 14 abr. 2013.

ONG REPÓRTER BRASIL. PAPEL SOCIAL DE COMUNICAÇÃO. Conexões sustentáveis São Paulo - Amazônia: quem se beneficia com a destruição da Amazônia. Outubro de 2008. Disponível em: <www.reporterbrasil.org.br/documentos/conexoes_ sustentaveis.pdf>. Acesso em: 20 abr. 2010.

ORGANIZAÇÃO INTERNACIONAL DO TRABALHO. Combatendo o trabalho escravo contemporâneo: o exemplo do Brasil. Brasília, DF: OIT, 2010.

PACTO Nacional de Erradicação do Trabalho Escravo. Disponível em: <http://www.reporterbrasil.org.br/ pacto/conteudo/view/4>. Acesso em: 6 jan. 2012.

PEROSA, J. M.; VIEIRA, E. M.; NITZSCHE, T. Cadeia produtiva da nêspera na região do alto Tietê: indicadores econômicos da produção e mercado atacadista. Revista Brasileira de Fruticultura, Jaboticabal, SP, v. 28, n. 2, p. 214-217, ago. 2006. PORTO, M. F. S. Saúde, trabalho e ambiente nos territórios da exclusão: elementos para uma promoção da saúde transformadora no Brasil. Bahia Análise $\mathcal{E}$ Dados, Salvador, v. 10, n. 4, p. 245-252, 2001.
. Saúde do trabalhador e o desafio ambiental: contribuições do enfoque ecossocial, da ecologia política e do movimento pela justiça ambiental. Ciência \& Saúde Coletiva, Rio de Janeiro, v. 10, n. 4, p. 829-839, 2005.

. Uma ecologia política dos riscos: princípios para integrarmos o local ao global na promoção da saúde e da justiça ambiental. Rio de Janeiro: Fiocruz, 2007.

POSSAS, C. A. Social ecosystem health: confronting the complexity and emergence of infectious diseases. Cadernos de Saúde Pública, Rio de Janeiro, v. 17, n. 1, p. 31-41, 2001.

PROCHNIK, V.; HAGUENAUER, L. Cadeias produtivas e oportunidades de investimentos no Nordeste Brasileiro. Revista Análise Econômica, Rio Grande do Sul, v. 20, n. 38, p. 143-161, set. 2002.

RONCALLI, A. G. O desenvolvimento das políticas públicas de saúde no Brasil e a construção do Sistema Único de Saúde. In: PEREIRA, A. C. (Org.). Odontologia em Saúde Coletiva: planejando ações e promovendo saúde. Porto Alegre: Artmed, 2003. p. 28-49.

TAMBELLINI, A. T. Avanços na formulação de uma Política Nacional de Saúde no Brasil: as atividades subordinadas à área das relações produção e saúde. In: CONFERÊNCIA NACIONAL DE SAÚDE DOS TRABALHADORES, 1., 1986, Brasília, DF. Anais... Rio de Janeiro: Cesteh/Ensp/Fiocruz, 1988. Mimeografado.

VASCONCELLOS, L. C. F. Saúde, trabalho e desenvolvimento sustentável: apontamentos para uma política de Estado. 2007. 421 f. Tese (Doutorado em Saúde Pública)-Escola Nacional de Saúde Pública Sérgio Arouca, Fundação Oswaldo Cruz, Rio de Janeiro, 2007.

VERAS, D.; CESARA, M. Escravos do aço. Observatório Social em Revista, Florianópolis, n. 6, p. 10-24, jun. 2004.

WALTNER-TOEWS, D. An ecosystem approach to health and its applications to tropical and emerging diseases. Cadernos de Saúde Pública, Rio de Janeiro, v. 7, p. 7-36, 2001. Suplemento. 